\title{
PENGEMBANGAN BAHAN AJAR BERBASIS NILAI KARAKTER DI SD KOTA TERNATE PROVINSI MALUKU UTARA
}

\author{
Darmawati dan Sundari \\ Program Studi Pendidikan Guru Sekolah Dasar, Fakultas Ilmu Keguruan dan Ilmu Pendidikan, \\ Universitas Khairun Ternate \\ e-mail:darmawatyhadi@gmail.com dansundari_sagi@yahoo.co.id
}

\begin{abstract}
Abstract: A research development of teaching materials in the form of characterbased worksheets. This research is aimed at developing producing output an elementary teaching materials based on the character value addition through this research are expected to: 1) provide accurate information to organizations / institutions / groups ber- competent to teach students to use materials ajarberbasisnilai right character in Basic pendidikanSekolah levels; 2) the development of strategies and policies that will be recommended from this research can be a direction for developm-ment-based learning models karakterdi value formal education, 3) prod- ucts of this study can be a reference for the Department of Education in policy decisions ber- connection with efforts to improve the quality of education in North Maluku in obtaining appropriate teaching materials in elementary school education. The results of this study indicate that that the teaching materials developed are worksheets grade 5 semesters 1 with the theme of Ben-da-objects in the surrounding environment. Integrating the value of the character in the worksheets to follow the curriculum in 2013 with thematic integrative approach. LKS validation results developed are still in pretty decent categories used so that still needs to be revised and improved in the development of the next stage.
\end{abstract}

\begin{abstract}
Abstrak: Telah dilakukan penelitian pengembangan bahan ajar berbentuk LKS berbasis karakter. Penelitian ini merupakan penelitian pengembangan yang bertujuan menghasilkan out put suatu bahan ajar SD berbasis nilai karakter Selain itu melalui penelitian ini diharapkan dapat: 1) memberikan informasi yang akurat kepada organisasi/lembaga/kelompok yang berkompeten untuk mengajarkan kepada anak didik dengan memakai bahan ajarberbasisnilai karakter yang tepat di jenjang pendidikanSekolah Dasar; 2) strategi pengembangan dan kebijakan yang akan direkomendasikan dari penelitian ini dapat menjadi arahan bagi pengembangan model-model pembelajaran berbasis nilai karakterdi jenjang pendidikan formal, 3) hasil penelitian ini dapat menjadi acuan bagi Dinas pendidikan dalam penentuan kebijakan berkaitan dengan upaya peningkatan mutu pendidikan di Maluku Utara dalam memperoleh bahan ajar yang tepat pada jenjang pendidikan Sekolah Dasar. Hasil penelitian ini menunjukkan bahwa bahwa bahan ajar yang dikembangkan adalah LKS kelas 5 semester 1 dengan tema benda-benda di lingkungan sekitar. Pengintegrasian nilai karakter dalam LKS mengikuti kurikulum 2013 dengan pendekatan tematik Integratif. Hasil validasi LKS yang dikembangkan masih dalam kategori cukup layak digunakan sehingga masih perlu dilakukan revisi dan perbaikan dalam pengembangan tahap berikutnya.
\end{abstract}

Kata Kunci: bahan ajar, lembar kerja siswa, nilai karakter, sekolah dasar kota ternate

\section{PENDAHULUAN}

Bahan ajar berbasis Nilai Karakter merupakan salah satu permasalahan umum dalam peningkatan dan perbaikan mutu pembelajaran di SD, khususya di Maluku Utara, akan tetapi ada yang lebih khusus lagi dalam hal penerapan model/metode pembelajaran dalam konteks keilmuan tertentu yang akan diterapkan pada anak didik dalam memperoleh pembelajaran melaui jenjang pendidikan formal. Penelitian ini bertujuan mengembangkan berbasis bahan ajar Nilai karakter masyarakat kepulauan dan kemajemukan pada pendidikan Sekolah Dasar. Menurut Zuhcdi (2010) pendidikan karakter rupanya mulai mendapatkan perhatian dari pemerintah untuk segera diimplementasikan di sekolah maupun 
perguruan tinggi yang ada di Indonesia sebagai program utama. Kepmendiknas dalam hal ini telah mencanangkan visi dan misi penerapan pendidikan karakter pada tahun 2010-2015. Penerapan pendidikan karakter memerlukan pemahaman yang jelas tentang konsep pempembentukan karakter (character building) dan pendidikan karakter (character education) itu sendiri.Tanpa pijakan konsep yang jelas dan pemahaman konsep yang komperatif visi ini bisa-bisa sebatas retorika belaka. Untuk itu menerbitkan kajian tentang konsep pendidikan karakter secara tepat sesuai diharapkan.Salah satu poin penting dari tugas pendidikan adalah membangun karakter (character building) anak didik. Rustaman (2007) menyatakan bahwa karakter merupakan standar-standar batin yang terimplementasi dalam berbagai bentuk kualitas diri Karakter diri dilandasi nilai-nilai serta cara berpikir berdasakan nilai-nilai tersebut dan terwujud didalam perilaku. Bentuk-bentuk karakter yang dikembangkan telah dirumuskan secara berbeda. Indonesia Heritage Foundation merumuskan beberapa bentuk karakter yang harus ada dalam diri setiap individu bangsa Indonesia di antaranya; "cinta kepada allah menciptakan alam semesta dan isinya, tanggung jawab, disiplin dan mandiri, jujur, hormat dan santun, kasih sayang, peduli dan kerjasama, percaya diri, kreatif, kerja keras dan pantang menyerah, keadilan dan kepemimpinan, baik dan rendah hati, toleransi, cinta damai dan persatuan."

Bentuk bahan ajar yang dikembangkan dalam penelitian ini yaitu berupa bahan ajar cetak yaitu sejumlah bahan yang disiapkan dalam kertas, yang dapat berfungsi untuk keperluan pembelajaran dan penyampaian informasi. Bahan ajar cetak dalam penelitian ini adalah bahan ajar berbentuk modul kumpulan LKS tematik integratif.

Bahan ajar yang akanditerapkan dalam proses pembelajaran memiliki bentuk dan fungsinya masing-masing. Bentuk bahan ajar menurut (Sunardjo, 2008) terdiriatas: Bahan cetak (printed) seperti : handout, buku, modul, lembar kerja siswa, brosur, leaflet, dan wall chart. Bahan ajar pandang dengar (audio visual) seperti : film/video, danvideo compact disk. Bahan ajar dengar (audio) seperti : kaset, radio, piringan hitam, dan compact disk audio. Bahan ajar pandang (visual) seperti: foto, gambar dan model/maket. Bahan ajar multimedia interaktif (interaktive teaching material) seperti: $\mathrm{CD}$ interaktif, computer based, dan internet. Bentuk bahan ajar yang dikembangkan dalam penelitian ini yaitu berupa bahan ajar cetak yaitu sejumlah bahan yang disiapkan dalam kertas, yang dapat berfungsi untuk keperluan pembelajaran dan penyampaiian informasi. Bahan ajar cetak dalam penelitian ini adalah bahan ajar berbentukmodul kumpulan LKS tematik integratif.

Dewasa ini telah banyak bahan ajar yang digunakan dalam pelaksanaan proses belajar mengajar, Salah satu alternatif pembelajaran yang dapat digunakan adalah pendekatan pembelajaran PAKEM. Model dan motode serta bahan ajar yang dikembangkan tidak terlepas dari kurikulum nasional yang berlaku dalam hal ini adalah Kurikulum 2013. Dalam prinsip-prinsip pengembangan kurikulum 2013 bahwa pendidikan yang diselenggarakan harus seimbang antara hasil belajar ranah sikap, keterampilan dan pengetahuan. Hal tersebut nampak jelas pada struktur kurikulum 2013 tegas mengkonsep standar isi dalam kompetensi inti sikap spiritual (KI1), sikap sosial (KI2) pengetahuan (KI3) dan Keterampilan (KI4).

Berdasarkan hasil observasi diketahui bahwa saat ini pada jenjang pendidikan dasar dan menengah sedang disosialisasikan implementasi Kurikulum 2013 dengan struktur kurikulum, pendekatan dan dan bahan ajar yang digunakan dalam implementasi Kurikulum 2013. Pelaksanaan sosialisasi Kurikulum 2013 tersebut sejauh ini belum maksimal dan masih tahap implementasi skala piloting di sekolah. Penelitian ini bertujuan untuk membantu pelaksanaan sosialisasi pendidikan berkarakter dan menemukan desain bahan ajar pengajaran yang sesuai dengan karakter masyarakat pesisir pada jenjang pendidikan Sekolah Dasar di kota Ternate.Kurikulum 2013 telah menyediakan bahan ajar formal dalam bentuk paket Buku guru dan buku siswa yang telah direvisi, namun implementasi di sekolah masih sangat minim karena paket buku tersebut belum ada, sehingga upaya perbanyakan secara mandiri oleh sekolah juga merupakan kendala bagi guru. Penelitian ini berupaya untuk mendesain bahan ajar yang bersifat pelengkap atau pendamping Buku Guru dan Buku siswa di sekolah piloting. 
Penelitian ini bertujuan untuk: 1). Melaksanakan sosialisasi tentang pendidikan karakter bagi guru Sekolah dasar, 2). Mengembangkan Bahan ajar pembelajaran berkarakter di SD, 3) $\mathrm{Me}$ ngembangkan Strategi perencanaan pembelajaran karakter yang efektif dan efisien melalui pengembangan buku ajar berkarakter yang mengena pada tujuan yang diharapkan dan dapat diterapkan melalui berbagai pendekatan dalam proses pembelajaran yang sesuai dengan implementasi Kurikulum 2013.

\section{METODE}

Penelitian ini merupakan penelitian pengembangan yang bertujuan menghasilkan produk dari kegiatan pengembangan, yaitu Bahan ajar berbasis nilai karakter. Instrumen penelitian yang digunakan dalam penelitian ini berupa :

1) Produk desain bahan ajar yang divalidasi.

2) Angket respon validator produk (Guru SD).

3) Angket respon validator ahli (Dosen PGSD).

Prosedur penelitian yang dilakukan adalah sebagai berikut:

1. Mengkaji KI (Kompetensi Inti) dan KD (kompetensi dasar) sesuai dengan materi yang akan diajarkan. Pada kurikulum 2013 di sekolah dasar mendesain pembelajaran Tematik Integratif, Pada penelitian tahap I ini bahan ajar yang dikembangkan adalak LKS Pendamping Buku Siswa kelas 5 semester 1 dengan Tema Benda-Benda di Sekitar Kita yang teriri dari 5 sub tema.

2. DesainBahan Ajar

a. Bahan ajar yang digunakan adalah LKS berbasis Nilai Karakter budaya masyarakat pesisir yang diturunkan dan didesain sesuai Buku Siswa kelas 5 pada kurikulum 2013, Pada LKS ini diintegrasikan nilai karakter budaya masyarakat pesisir dengan sajian peristiwa kontekstual disekitar. b. Gambar-gambar yang disajikan dalam bahan ajar yaitu berupa peristiwa dikota Ternate dan Maluku utara yang diadopsi dari Buku siswa.

c. Gambar-gambar yang ditampilkan di bahan ajar yaitu merupakan gambar yang berwarna sehingga menarik perhatian siswa.

d. LKS yang didesain diperkaya pendalaman materi untuk siswa.

3. Validasi bahan ajar

a. Desain validasi

Desain validasi yang digunakan pada penelitian pengembangan ini adalah validasi dari bahan ajar dan guru sebagai pengguna produk.Validasi meliputi validasi rancangan produk dalam hal bahan ajar yang didesain oleh peneliti.Validasi ini bertujuan untuk memperoleh data berupa penilaian dan saran validator, sehingga diketahui valid tidaknya bahan ajar yang dikembangkan dan selanjutnya digunakan sebagai dasar untuk melakukan revisi.

b. Subjekvalidasi

Pada penelitian pengembangan bahan ajar LKS berbasis Karakter ini validasi terhadap bahan ajar yang telah didesain divalidasi oleh guru dan dosen mengenai kelayakan bahan ajar tersebut. Pengumpulan data dilakukan dengan mengumpulkan angket yang berasal dari guru dan dosen (validator produk dan validator ahli).

Analisis data dilakukan perhitungan prosentasi nilai melalui hasil angket dengan langkah-langkah sebagai berikut:

1. Menghitung prosentase data dengan menggunakan formulasi rumus sebagai berikut:

$\mathrm{P}=\frac{\sum \mathrm{x}}{\sum \mathrm{xi}} \mathrm{x} 100 \%$

Dimana:

$\mathrm{P}$ : Prosentase 
$\Sigma x$ : Jumlah jawaban penilaian Exi : Jumlah jawaban tertinggi

2. Setelah nilai prosentase diperoleh maka ditafsirkan dalam kalimat sebagaimana dikemukakan oleh Arikunto (2006).

\begin{tabular}{|c|c|}
\hline Prosentase & Kriteriavalidasi \\
\hline $76-100$ & Valid \\
\hline $56-75$ & Cukup Valid \\
\hline $40-55$ & Kurang valid ( revisi) \\
\hline $0-39$ & Tidak valid (revisi) \\
\hline
\end{tabular}

\section{HASIL DAN PEMBAHASAN}

Data hasil penilaian terhadap Bahan ajar LKS ini diperoleh dari validator yang terdiri dari: Lima (5) orang dosen PGSD FKIP Uni- versitas Khairun, dan 3 orang guru model serta 3 kepala sekolah tempat penelitian di kota Ter- nate yaitu SD Tubo (kota Ternate Utara), SDN Akemalako (kota Ternate tengah) dan SDN 2 Gambesi (kota Ternate selatan).

Data hasil penilaian berupa kritik, tang- gapan, saran, masukan dan penilaian diper- gunakan untuk merevisi perangkat pembela- jaran.

\section{Data Kuantitatif}

Data kuantitatif berupa penilaian perang- kat pembelajaran yang berupa angka-angka 4, 3, 2, dan 1. Data hasil validasi penilaian pe- rangkat pembelajaran yang dikembangkan, di- sajikan pada Tabel 4.1 berikut ini:

Tabel.1 Data Hasil Validasi Penilaian Bahan Ajar LKS berkarakter yang dikembangkan

\begin{tabular}{|c|c|c|c|c|c|c|c|c|}
\hline \multirow{2}{*}{$\begin{array}{l}\text { Aspek } \\
\text { yang } \\
\text { dinilai }\end{array}$} & \multirow[t]{2}{*}{$\begin{array}{l}\text { Kriteri } \\
\text { a }\end{array}$} & \multirow{2}{*}{$\begin{array}{l}\text { Jumlah } \\
\text { Item } \\
\text { Pertany } \\
\text { aan }\end{array}$} & \multicolumn{4}{|c|}{$\begin{array}{l}\text { Pilihan } \\
\text { Jawaban }\end{array}$} & \multirow{2}{*}{$\begin{array}{l}\text { Pers } \\
\text { en } \\
\text { Rat } \\
\text { a- } \\
\text { rata } \\
(\%)\end{array}$} & \multirow[t]{2}{*}{$\begin{array}{l}\text { Ketera } \\
\text { ngan }\end{array}$} \\
\hline & & & 4 & 3 & 2 & 1 & & \\
\hline & $\begin{array}{l}\text { Bagian } \\
\text { Pengan } \\
\text { tar }\end{array}$ & 4 & 8 & $\begin{array}{l}2 \\
4\end{array}$ & & & 65 & $\begin{array}{l}\text { Cukup } \\
\text { valid }\end{array}$ \\
\hline & $\begin{array}{l}\text { Integra } \\
\text { si Nilai } \\
\text { karakte } \\
\mathrm{r}\end{array}$ & 1 & & 8 & & & 60 & $\begin{array}{l}\text { Cukup } \\
\text { valid }\end{array}$ \\
\hline & Format & 1 & & 8 & & & 60 & Cukup \\
\hline
\end{tabular}

\begin{tabular}{|c|c|c|c|c|c|c|c|}
\hline & LKS & & & & & & valid \\
\hline & $\begin{array}{l}\text { Uraian } \\
\text { kegiata } \\
\text { n siswa }\end{array}$ & 5 & $\begin{array}{l}1 \\
2\end{array}$ & $\begin{array}{l}2 \\
4\end{array}$ & 4 & 64 & $\begin{array}{l}\text { Cukup } \\
\text { valid }\end{array}$ \\
\hline & $\begin{array}{l}\text { Gamba } \\
\text { r } \\
\text { Ilustras } \\
\text { i }\end{array}$ & 3 & 6 & $\begin{array}{l}1 \\
2\end{array}$ & 6 & 65 & $\begin{array}{l}\text { Cukup } \\
\text { valid }\end{array}$ \\
\hline & $\begin{array}{l}\text { Evalua } \\
\text { si }\end{array}$ & 4 & & $\begin{array}{l}3 \\
2 \\
\end{array}$ & & 60 & $\begin{array}{l}\text { Cukup } \\
\text { valid }\end{array}$ \\
\hline \multirow[t]{7}{*}{ Konten } & $\begin{array}{l}\text { Bagian } \\
\text { Pengan } \\
\text { tar }\end{array}$ & 4 & & $\begin{array}{l}2 \\
4\end{array}$ & 8 & 65 & $\begin{array}{l}\text { Cukup } \\
\text { valid }\end{array}$ \\
\hline & $\begin{array}{l}\text { Integra } \\
\text { si Nilai } \\
\text { Karakt } \\
\text { er }\end{array}$ & 1 & & 8 & & 60 & $\begin{array}{l}\text { Cukup } \\
\text { valid }\end{array}$ \\
\hline & $\begin{array}{l}\text { Format } \\
\text { LKS }\end{array}$ & 1 & & 8 & & 60 & $\begin{array}{l}\text { Cukup } \\
\text { valid }\end{array}$ \\
\hline & $\begin{array}{l}\text { Uraian } \\
\text { Materi }\end{array}$ & 6 & & $\begin{array}{l}4 \\
8\end{array}$ & & 65 & $\begin{array}{l}\text { Cukup } \\
\text { valid }\end{array}$ \\
\hline & $\begin{array}{l}\text { Kegiat } \\
\text { an } \\
\text { belajar } \\
\text { siswa }\end{array}$ & 5 & 8 & $\begin{array}{l}2 \\
4\end{array}$ & 8 & 64 & $\begin{array}{l}\text { Cukup } \\
\text { valid }\end{array}$ \\
\hline & $\begin{array}{l}\text { Ilustras } \\
\text { i } \\
\text { Gamba } \\
\text { r }\end{array}$ & 3 & 6 & $\begin{array}{l}1 \\
2\end{array}$ & 6 & 65 & $\begin{array}{l}\text { Cukup } \\
\text { valid }\end{array}$ \\
\hline & $\begin{array}{l}\text { Evalua } \\
\text { si }\end{array}$ & 4 & & $\begin{array}{l}3 \\
2\end{array}$ & & 60 & $\begin{array}{l}\text { Cukup } \\
\text { valid }\end{array}$ \\
\hline Jumlah & & 48 & & & & & $\begin{array}{l}\text { Cukup } \\
\text { valid }\end{array}$ \\
\hline
\end{tabular}

Sumber data primer diolah

Berdasarkan data di atas dapat diketahui bahwa produk LKS yang dikembangkan masih dalam kategori cukup valid untuk aspek peng- antar, integrasi nilai karakter uraian materi, uraian kegiatan siswa dan ilustrasi gambar serta evaluasi, dengan demikian produk masih perlu diperbaiki dan revisi.

\section{Data Kualitatif}

Data kualitatif hasil validasi berupa komentar atau tanggapan dan saran dari vali- dator terhadap bahan ajar LKS yang dikem- bangkan. Komentar dan saran ini dibagi men- jadi dua bagian yaitu komentar dan saran yang bersifat khusus dan komentar yang bersifat umum.

\section{a. Komentar dan Saran yang bersifat} Khusus

Komentar dan Saran yang bersifat khusus berisi tentang komentar dan saran mengenai isi Bahan ajar LKS sebagai berikut: 
Data hasil validasi komentar dan saran terhadap isi LKS yang dikembangkan disajikan dalam Tabel 2 berikut:

\begin{tabular}{|c|c|c|c|}
\hline No & $\begin{array}{l}\text { Bagian } \\
\text { Perangkat } \\
\text { Pembelajara } \\
\mathrm{n}\end{array}$ & Halaman & Komentar dan saran \\
\hline 1 & $\begin{array}{l}\text { Halaman } \\
\text { Judul }\end{array}$ & & $\begin{array}{l}\text { *Sebaiknya } \\
\text { tampilan gambar } \\
\text { lebih bisa mewakili } \\
\text { kegiatan yang } \\
\text { berkaitan dengan } \\
\text { benda benda di } \\
\text { lingkungan sekitar. } \\
\text { *Tulisan papan } \\
\text { sekolah digabung } \\
\text { dengan foto sekolah } \\
\text { *Cukup menarik } \\
\text { tapi jangan } \\
\text { menggunakan } \\
\text { Pendamping Buku } \\
\text { siswa dan Tema } \\
\text { dinaikkan } \\
\text { tulisannya' }\end{array}$ \\
\hline 2 & $\begin{array}{l}\text { Kata } \\
\text { pengantar, } \\
\text { Petunjuk } \\
\text { penggunaan } \\
\text { LKS, Desain } \\
\text { pembelajara } \\
\text { n dan sistem } \\
\text { penilaian }\end{array}$ & & $\begin{array}{lr}\text { * Kata pengantar } \\
\text { cukup jelas } & \text { dan } \\
\text { operasional } & \\
* \text { petunjuk } & \text { LKS } \\
\text { disesuaikan } & \text { setiap } \\
\text { sub tema } & \\
\text { *LKS } & \text { sudah } \\
\text { menerapkan } & \\
\text { Saintific } & \end{array}$ \\
\hline 3 & $\begin{array}{l}\text { Ilustrasi } \\
\text { gambar }\end{array}$ & & $\begin{array}{l}\text { *Gambar dan } \\
\text { pertanyaan di cek } \\
\text { lagi sinkronisasinya } \\
\text { *Keterangan } \\
\text { gambar konsisten di } \\
\text { bawah }\end{array}$ \\
\hline 4 & $\begin{array}{l}\text { Integrasi } \\
\text { nilai } \\
\text { karakter }\end{array}$ & & $\begin{array}{lr}\text { Tulisan karakter } \\
\text { dihilangkan saja } \\
\text { karena sudah ada } \\
\text { KI1 dan KI2 }\end{array}$ \\
\hline 5 & $\begin{array}{l}\text { Uraian } \\
\text { materi }\end{array}$ & & $\begin{array}{l}\text { Perlu ditambahkan } \\
\text { uraian materi }\end{array}$ \\
\hline 6 & $\begin{array}{l}\text { Uraian } \\
\text { kegiatan } \\
\text { siswa } \\
\end{array}$ & & Sudah bagus \\
\hline 7 & $\begin{array}{l}\text { Evaluasi/tug } \\
\text { as }\end{array}$ & & $\begin{array}{lr}\text { Belum maksimal } & \text { perlu } \\
\text { jadi } & \text { yang } \\
\text { ditambahkan } & \text { dan } \\
\text { operasional } & \text { dentik } \\
\text { autention }\end{array}$ \\
\hline 8 & $\begin{array}{l}\text { Daftar } \\
\text { pustaka }\end{array}$ & & $\begin{array}{l}\text { Diperkaya lagi } \\
\text { sesuai dengan } \\
\text { uraian materi }\end{array}$ \\
\hline
\end{tabular}

Sumber: data Primer diolah

Berdasarkan data di atas maka dapat diketahui bahwa secara khusus aspek-aspek pengembangan produk masih perlu diperbaiki pada setiap item pengembangan.

\section{a. Komentar dan Saran yang bersifat umum}

Komentar dan Saran yang bersifat umum berisi tentang komentar dan saran mengenai isi Bahan ajar LKS sebagai berikut:

Data hasil validasi komentar dan saran terhadap isi LKS yang dikembangkan disajikan dalam Tabel 3 berikut:

\begin{tabular}{|l|l|l|}
\hline No & $\begin{array}{l}\text { Bagian Perangkat } \\
\text { Pembelajaran }\end{array}$ & Komentar dan saran \\
\hline 1 & $\begin{array}{l}\text { Kemenarikan } \\
\text { produk }\end{array}$ & $\begin{array}{l}\text { LKS yang dikembangkan } \\
\text { sudah bagus dan inovatif }\end{array}$ \\
\hline 2 & Kelayakan Produk & $\begin{array}{l}\text { LKS layak digunakan } \\
\text { sebagai pelengkap buku } \\
\text { siswa yang belum ada di } \\
\text { sekolah } \\
\text { LKS sangat kontekstual } \\
\text { dengan karakter masyarakat } \\
\text { Ternate }\end{array}$ \\
\hline
\end{tabular}

Sumber: Data primer diolah

Berdasarkan data di atas dapat diketahui bahwa produk yang dikembangkan sudah cukup layak digunakan sebagai pendamping buku siswa kurikulum 2013.

\section{Hasil Validasi Terhadap Bahan ajar LKS berbasis karakter}

Berdasarkan analisis data dapat diketahui bahwa hasil validasi produk bahan ajar LKS berbasis karakter rata-rata nilai validasi pada aspek desain dan konten LKS sebesar 63,5\% kategori cukup Valid, dan masih perlu diperbaiki dalam pengembangan produk berikutnya. Ujivalidasiproduk bahan ajar LKS berbasis karakter di SD kota Ternate membuktikan hasil bahwa LKS yang dikembangkan oleh peneliti berdasarkan uji coba pembelajaran di kelas oleh guru model secara praktik cukup valid dan layak digunakan. Riyana (2004) mengemukakan bahwa pembelajaran pada hakikatnya merupakan komunikasi yang transaksional yang bersifat timbal balik baik diantara guru dengan siswa maupun siswa dengan siswa dan lingkungan belajar dalam upaya pencapaian tujuan pembelajaran. Dari makna pembelajaran di atas terdapat makna inti bahwa pembelajaran 
harus mengandung unsur komunikasi dan informasi, dengan demikian produk dan proses teknologi yang dibutuhkan dalam pembelajaran sesuai dengan karakteristik tersebut, dengan demikian teknologi yang berhubungan langsung dengan pembelajaran salah satunya adalah bahan ajar baik cetak seperti LKS dan buku serta bahan ajar audio visual (Jalal, 2011). Bahan ajar LKS yang dikembangkan dalam penelitian ini masih dalam kategori cukup Layak digunakan, hal ini karena kondisi transisi kurikulum yang berlaku harus peneliti sesuaikan dengan desain produk, sehingga dengan berlakunya kurikulum 2013 yang relatif baru menyebabkan bahan ajar yang dikembangkan masih belum maksimal. Zulkarnain (2009) menyatakanada tiga prinsip yang diperlukan dalam mengembangkan bahan ajar.Ketiga prinsip itu adalah relevansi, konsistensi dan kecukupan.Prinsip relevansi artinya keterkaitan atau berhubungan erat. Materi pembelajaran hendaknya relevan memiliki keterkaitan antara bahan ajar dengan pencapaian standar kompetensi dan kompetensi dasar. Prinsip konsistensi artinya keajegan antara bahan ajar dengan kompetensi dasar yang harus dikuasai siswa. Misalnya, kompetensi dasar yang harus dikuasai siswa empat macam, maka bahan ajar yang harus diajarkan juga harus meliputi empat macam. Prinsip kecukupan artinya materi yang diajarkan hendaknya cukup memadai dalam membantu siswa menguasai kompetensi dasar yang diajarkan. Materi tidak boleh terlalu sedikit, dan tidak boleh terlalu banyak. Jika terlalu sedikit akan kurang membantu mencapai standar kompetensi dan kompetensi dasar. Sebaliknya, jika terlalu banyak akan membuang-buang waktu dan tenaga yang tidak perlu untuk mempelajari nya (Kemendiknas, 2011). Hasil penelitian ini menunjukkan bahwa pengembangan bahan ajar memerlukan analisa swot terhadap aspek kesesuaian kurikulum, karakter budaya, kecukupan konsep, dan motivasi siswa. Bahan ajar LKS berbasis karakter ini merupakan salah satu inovasi tim peneliti dalam mengimplementasikan kurikulum 2013 yang secara umum dilapangan masih perlu penyesuaian dan pembenahan yang urgen. LKS berbasis karakter ini menerapkan pendekatan Scientific dalam implementasi kurikulum 2013 dan juga tematik integratif dengan pengintegrasian nilai karakter masyarakat pesisir di kota Ternate dan Maluku utara.

\section{KESIMPULAN}

Dari hasil penelitian dapat disimpulkan sebagai berikut:

1. Produk desain bahan ajar berbasis karakter kelas 5 semester 1 tema "benda-benda di lingkungan sekitar" telah di ujicoba di SD kota Ternate dan di validasi dengan kategori cukup layak digunakan sebagai bahan ajar pendamping buku siswa kurikulum 2013.

2. Produk desain bahan ajar berbasis karakter masih perlu diperbaiki atau revisi untuk penyempurnaan hasil.

\section{SARAN}

Berdasarkan hasil penelitian ini maka dapat disaran hal-hal sebagai berikut:

1. Perlu dilakukan penelitian sejenis untuk analisa buku guru kurikulum 2013.

2. Perlu dilakukan penelitian pengembangan untuk jenis media atau bahan ajar lain yang diadaptif dengan kurikulum 2013.

\section{DAFTAR PUSTAKA}

Arikunto, 2006. Prosedur Analisa data. Jakarta Gramedia.

Education on "Science Education Facing Againt the Challenges of the $21^{\text {st }}$ Century". Indonesia University of 
ducation, Bandung: 27 October 2007.

Jalal, F. 2011. Akhlak dan Pembangunan Pendidikan Karakter. Milad JSIT, Februari.

Kemdiknas. 2011. Pendidikan Karakter di Perguruan Tinggi dalam Konteks Pengembangan Kebijakan Nasional Pendidikan Karakter. Sosialisasi Pendidikan Karakter, Medan 27-28 Mei 2011.

Permendiknas No. 22 Tahun 2006. Jakarta: Depdiknas.

PermenDiknas No. 65Tahun 2013.Jakarta: Depdiknas

Riyana,2004. Strategi dan Inovasi pembelajaran. Bandung: Rosda karya.

Rustaman, Nuryani Y. 2007. Basic Scientific Inquiry in Science Education and Its Assessment. Keynote Speaker in the First International Seminarof Science

SuyatadanDarmiyatiZuchdi. 2007.“Ary Ginanjar Agustian dan Gerakan Pembaruan Pendidikan Karakter dengan Optimalisasi Kecerdasan Emosional Spiritual". Pidato Promotor pada Pemberian Gelar Doctor Honoris Causa dalam Bidang Pendidikan Karakter kepada Ary Ginanjar Agustian. Yogyakarta: Universitas Negeri Yogyakarta.

Zuchdi, D., Prasetya, Z.K. dan Masruri, M.S. 2010. Pengembangan Model
Pendidikan Karakter Terintegrasi dalam Pembelajaran Bidang Studi di Sekolah Dasar. Cakrawala Pendidikan, Mei 2010, Th. XXIX, Edisi Khusus Dies Natalis 